\title{
Research on the Behavior of the Steel Plated Shear Wall by Finite Element Method
}

\author{
S. M. R. Mortazavi, ${ }^{1}$ M. Ghassemieh, ${ }^{2}$ and M. S. Ghobadi ${ }^{3}$ \\ ${ }^{1}$ Department of Civil Engineering, Shahid Rajaee Teacher Training University, Tehran 16788-15811, Iran \\ ${ }^{2}$ School of Civil Engineering, University of Tehran, Tehran 11265-4563, Iran \\ ${ }^{3}$ Department of Civil Engineering, West Tehran Branch, Islamic Azad University, Tehran 14619-88631, Iran \\ Correspondence should be addressed to M. Ghassemieh; mghassem@ut.ac.ir
}

Received 26 February 2013; Accepted 13 May 2013

Academic Editor: Zhongwei Guan

Copyright (c) 2013 S. M. R. Mortazavi et al. This is an open access article distributed under the Creative Commons Attribution License, which permits unrestricted use, distribution, and reproduction in any medium, provided the original work is properly cited.

From the early' 70s till today, steel shear walls have been used as the primary lateral force resisting system in some of the significant buildings around the world. To assist understanding the behavior of this system, there have been research programs in USA, Canada, Japan, and UK. This research presents the dynamic and cyclic behavior of steel plated shear wall. In order to simulate the behavior of such a wall structure, finite element method of analysis is implemented. Several analytical models are implemented, in order to obtain the dynamic as well as cyclic behavior of such system. The material nonlinearity as well as geometrical nonlinearity along with the postbuckling behavior of steel plate subjected to cyclic loading has also been employed. The hysteresis diagrams of steel shear wall system in terms of storey shear drift are presented. The results obtained from the analyses are compared to some experimental results reported by other researchers previously. The nonlinear time history analysis of such system is carried out for different seismic response spectra. Finally, the significant factors and parameters of the steel plated shear wall which affect the overall behavior of such system are acknowledged and their effects were recognized.

\section{Introduction}

Behavior of steel plate shear wall (SPSW) system appears to be similar to the behavior of the plate girder in which the beam acts as stiffener of the girder and column acts as flange of the girder, although columns appear to be much stiffer than plate girder flanges. The steel plate in the wall system is designed to withstand seismic loads or wind forces. The load transfer in the system is through the tension field action, in which the shear forces in the panel are resisted by the plate. As Basler [1] demonstrated for plate girders, the postbuckling tension field action of steel shear wall can supply significant strength, stiffness, and ductility. Performing many experiments on the steel shear wall system by the researchers [2-6], nowadays this lateral system is being utilized in the structural steel frames with thin plates and in most cases without stiffeners. The diagonal compression zone buckles when the plate is loaded in shear, and in the meantime the other diagonal zone will yield in tension. Following the unloading and reloading of the system, the buckled zone will transform back into diagonal tension zone. Even though parts of the plate buckle, the overall behavior of the SPSW system will remain stable during the cyclic loading, and consequently for the stability reasons, it is not normally required to provide the stiffeners for the plates. For such reasons, some experimental works have been carried out on the SPSW without having stiffeners [4]. It was revealed that for the cases when the opening exits in the wall system, in order to prevent the local instabilities, then the stiffeners must be provided.

Steel shear wall systems have been designed and used in some well-known tall buildings in the past three decades. Although a variety of forms of the SPSW have been studied and investigated, the unstiffened plate panel concept initiated by Timler and Kulak [2] and Driver et al. [3] at the University of Alberta in the early 1980s slowly was accepted in the steel industry. Since then, the use of this system along with the research program in this area has most commonly been used in North America. In Japan, the stiffened SPSW system has 


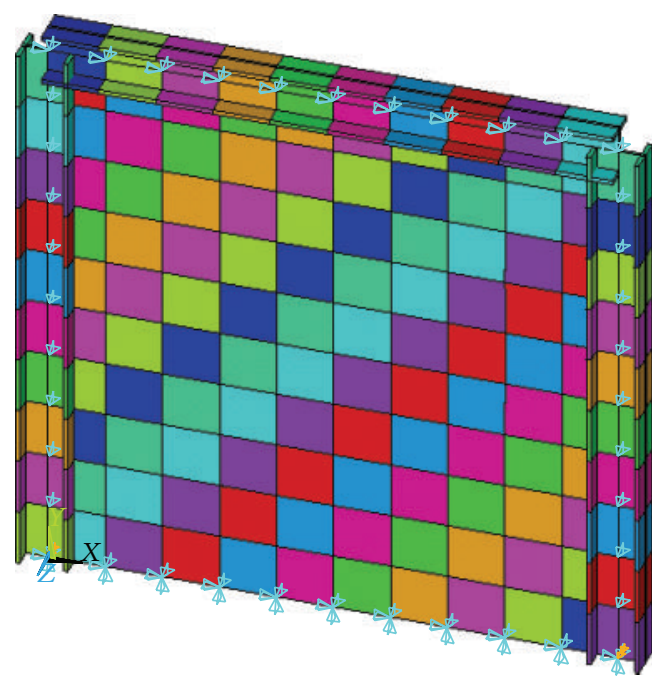

FIGURE 1: Typical finite element model of the SPSW system with shell elements.

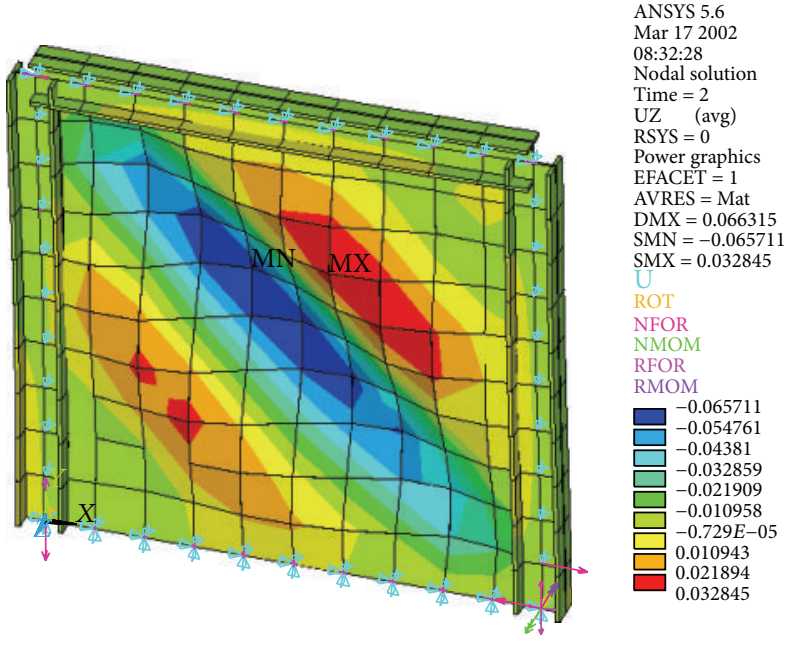

FIgURE 2: Deformation of the shell elements.

been more common. Some of those buildings that use the SPSW as their lateral force system have gone under significant seismic ground motion and all of them survived with minor damage. Today, this system has been recognized in NBCC of Canada [7] and AISC of USA [8].

The concept of utilizing the postbuckling strength of SPSW was developed by Thorburn et al. [9] and verified by Timler and Kulak [2]. Studies presented by Timler and Kulak [2] and Timler [10], to evaluate the ductility and hysteretic behavior of such SPSW designed with unstiffened infill plates, have confirmed their great energy dissipation capabilities.

Timler and Kulak [2] was the first group to conduct the cyclic tests on the steel shear wall without the stiffeners. They have reported that the postbuckling behavior of the plates was ideal, and they recommended the ductility ratio of four for such a system. They also proposed a diagonal tension field uniaxial model to predict the cyclic behavior of the plate system.
Driver et al. [3] conducted test on a four-storey building in which a shear plate steel wall was used without stiffeners. From their test results, they reported the ductility ratio of six for the steel wall system. Using the shell elements, they also proposed a simplified nonlinear finite element model which their computer models did not agree well with the test results.

Lubell et al. [4] tested four stories and one storey steel plate shear wall without stiffeners subjected to cyclic loadings. They reported a degree of ductility of six for their system and concluded that the existing of the steel shear plate in the frame results in the reduction of the rotation in the moment resisting connection and protects the frame from severe damage.

Elgaaly and Liu [5] tested three stories of SPSW subjected to cyclic loadings. They indicated that the nonlinear behavior of the system starts with yielding of the plate and the strength of the system would be controlled by the plastic hinge in the columns. On the other hand, they recommended that the steel plate wall yields before the buckling of the columns.

Astaneh-Asl [6] also studied the behavior of the unstiffened SPSW subjected to cyclic loadings. He reported that following the failure of the connections, the SPSW could still tolerate sixty percent of the lateral loadings before the failure of the system. This feature of the wall system can be very useful during the severe earthquake in which the system can still stand the lateral loadings before the final failure.

In this research, the behavior of SPSW system subjected to cyclic and dynamic loading is examined. Emphasis is placed on the structural behavior which is recognized via finite element analysis of the system. One of the finite element models suggested to represent SPSW is the strip or uniaxial model developed by Thorburn et al. [9]. This model is generally recognized for providing reliable assessments of ductility and ultimate strength. In this study, the uniaxial model is used as a basis to investigate the feasibility of pertinent parameters affecting the SPSW system. Parameters that can be considered to influence significantly on the structural behavior and force transfer mechanism, such as plate thickness, column stiffness, beam stiffness, plate aspect ratio and stiffeners, are also highlighted. Finally, the nonlinear dynamic analysis of the SPSW system subjected to Elcentro earthquake excitation is performed and the cyclic response as well as energy dissipation of the structure is assessed.

\section{Finite Element Analysis of the SPSW System}

First, for modeling the steel shear wall a test specimen from the work of Lubell et al. [4] which was a one storey frame with steel shear wall is chosen. The specimen consisted of $824 \mathrm{~mm} \times 824 \mathrm{~mm} \times 1.5 \mathrm{~mm}$ steel plate with the $\mathrm{S} 75 \times 8$ Canadian section for the beam and columns. According to the test program, all the connections were moment connections. For analyzing the finite element model, ANSYS [11] general computer program is used. For beam and columns, beam element 188 of the ANSYS program, and for the steel plate shell element 143 is selected in which both elements contain the plasticity effect and large deformation capabilities. The beam and columns are modeled by ten beam elements each, 


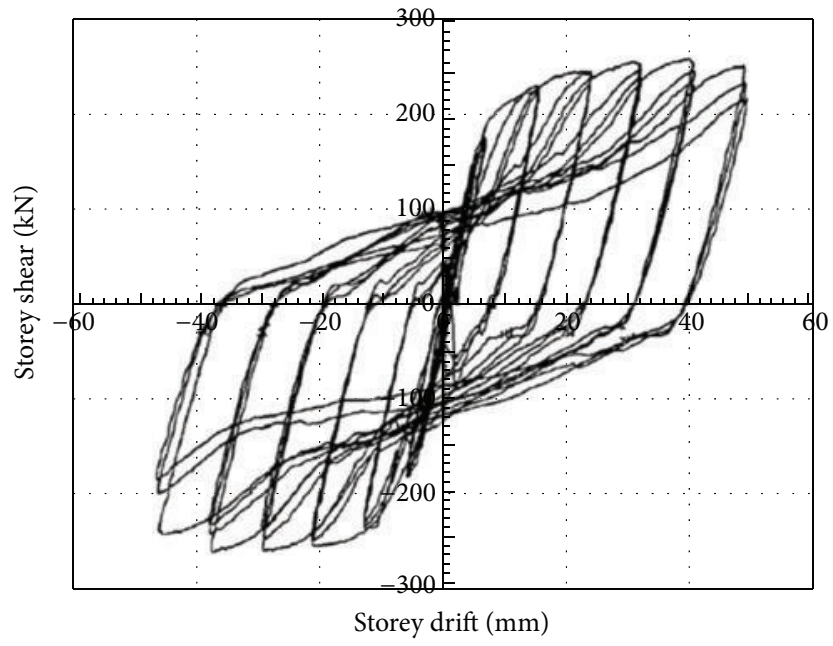

(a)

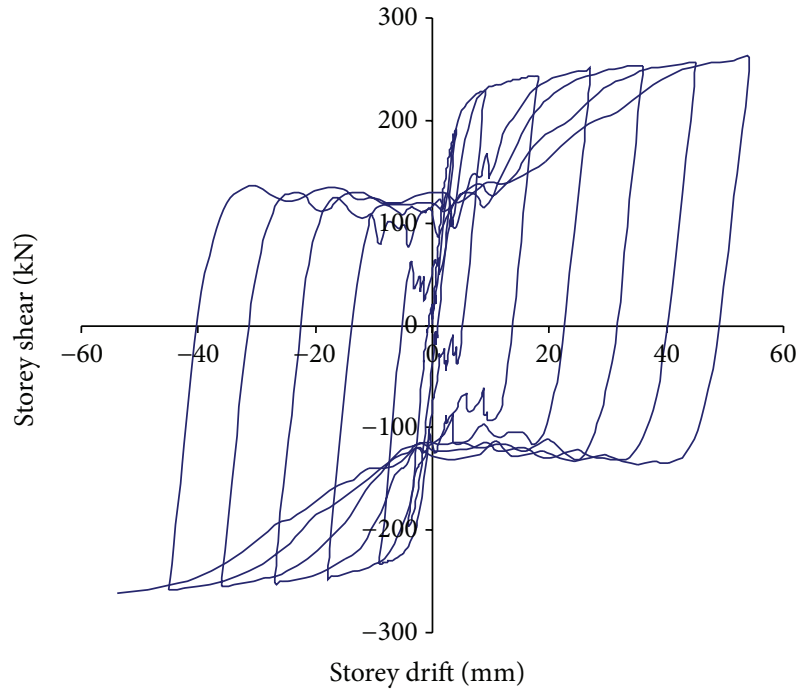

(b)

FIGURE 3: Shear force versus storey drift hysteresis of SPSW system. (a) Test result [4]. (b) Present numerical result with shell elements.

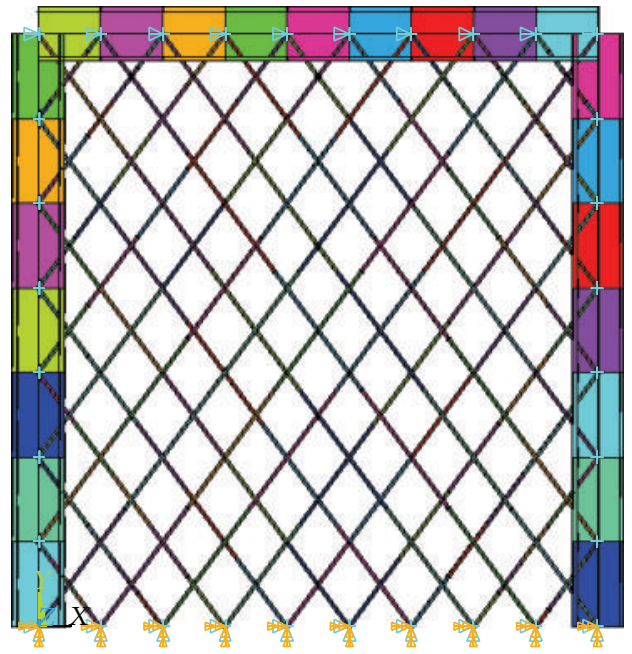

FIGURE 4: Finite element tension field model of the SPSW system with uniaxial elements.

and the steel plate was modeled by 100 shell elements (as shown in Figure 1). Because during the testing stages no out of plane buckling was reported in the columns and beam, then in the model the out-of-plane degrees of freedom of the beam and column nodes are restrained. The loading protocol for the analysis is synchronized in accordance with the test loading protocol as given by ATC-24 [12]. Both material and geometric nonlinearities are considered in the analysis. To start the nonlinear analysis, an initial out-ofplane displacement is imposed in the middle of the steel plate in order to have the first governing buckling mode of the plate to be initiated more rapidly. Typical nonlinear deformation of the system is illustrated in Figure 2. The hysteresis diagram of the storey shear versus the storey drift is given in Figure 3. Comparing the result of the test and analytical results reveals that the shell model predicts the cyclic behavior of the SPSW close to the test result. The results obtained from the finite element model show more energy dissipation when compared to the test results. The time required to analyze the model was 180 minutes on the Pentium IV (2Ghz/256 MB Ram). This indicated that structural analysis of such a model is very time consuming and thus very impractical for a simple one storey and one bay frame. Therefore, in order to expedite the analysis, a simple tension field uniaxial model proposed by Timler [10] was employed for further studying the behavior of SPSW system.

After recognizing the behavior of the SPSW system through modeling with the shell elements, then steel plate is modeled again, but this time with the diagonal tension field uniaxials as shown in Figure 4. These uniaxial elements yield in tension and buckle in compression. By treating the plate at each storey as a single pin-ended brace known as the equivalent storey brace model that runs along the diagonal of the bay, then the angle of these tension field uniaxials with respect to the column line is given by Timler [10] as follows:

$$
\tan ^{4} \alpha=\frac{(2 / t L)+\left(1 / A_{c}\right)}{(2 / t L)+\left(2 h_{s} / A_{b} L\right)+\left(h_{s}^{4} / 180 I_{c} L^{2}\right)} .
$$

It appears that the angle of the uniaxials obtained from the above equation for most steel shear wall thicknesses and practical beam and column sections is always within 3040 degrees with the column line. Figure 4 shows the model built using these diagonal tension field uniaxial elements with the angle of 35 degree with vertical line. In the model shown, the steel plate has been divided into fifteen strips, and therefore fifteen diagonal tension field uniaxials in two different directions are required. The accuracy of the result depends on the number of strips, and thus the more strips used in the model, the better the result gets, and it is suggested to use at least 10 strips in each direction. The area of each 


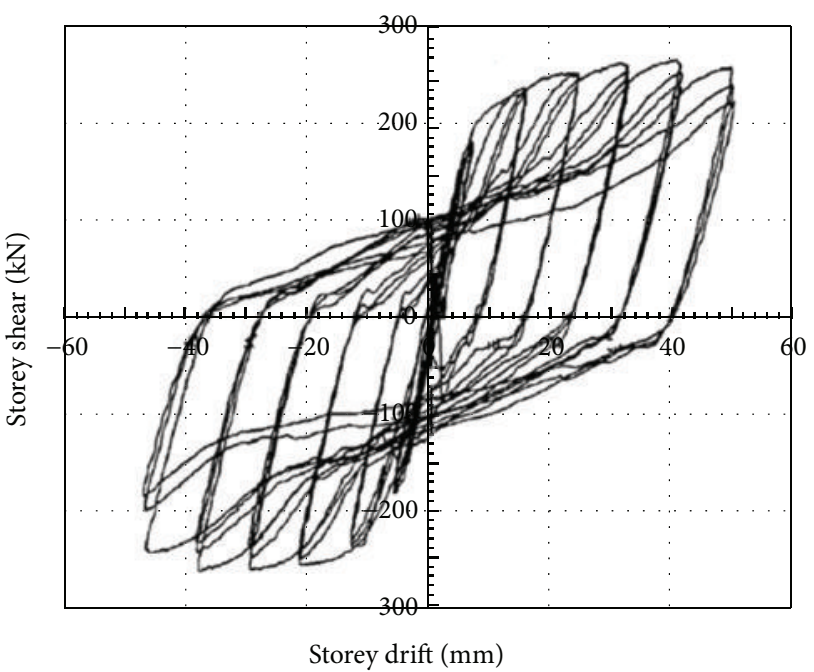

(a) Test result [4]

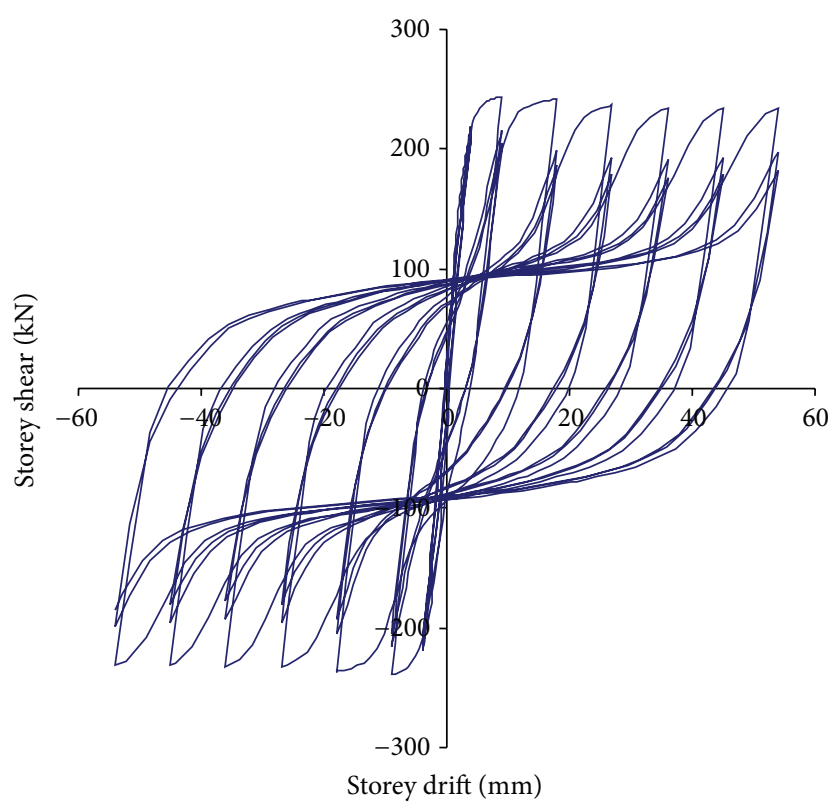

(b) Present theoretical results with uniaxial elements

FIGURE 5: Shear force versus storey drift hysteresis of SPSW system.

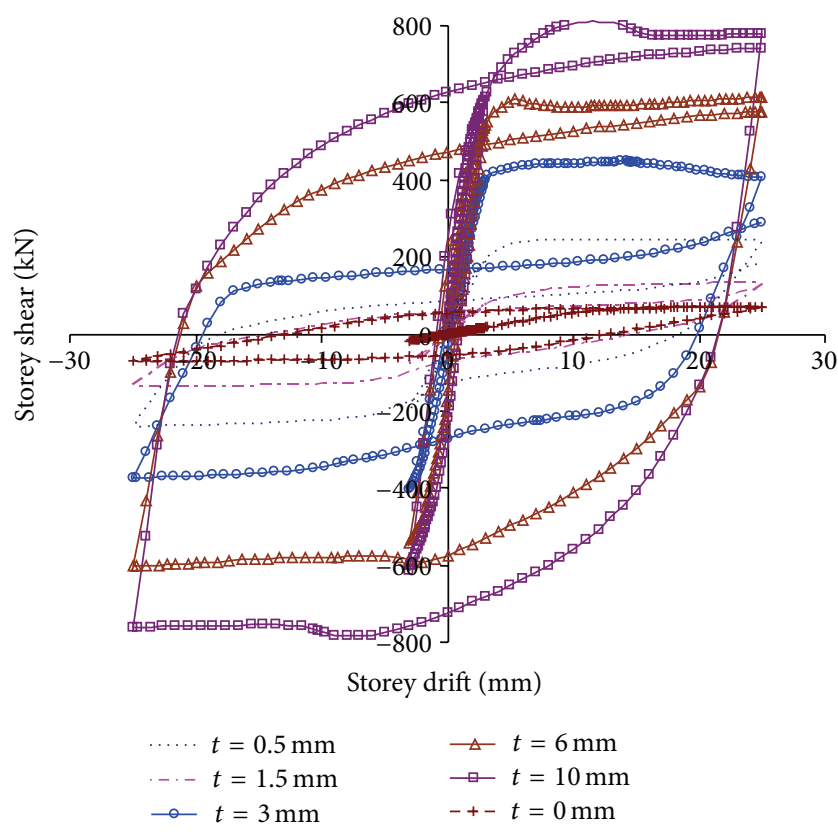

FIGURE 6: Effect of plate thickness on the hysteresis diagram.

uniaxial in each direction is equal to the strip cross section which is the strip width times the plate thickness. Due to cyclic nature of the loadings, the diagonal uniaxials crossing each other are not connected together on the steel plate plane. In fact, by this method the tensile and compression behavior of the plate is separated, and therefore the diagonal tension field uniaxials are placed in two different layers. In order to have the buckling of the diagonal uniaxial matched with theory, the uniaxials are divided into several elements. Here in this study, each diagonal uniaxial is divided into seven elements. For modeling the uniaxials, element type Beam 188 of the ANSYS computer program is used in the analysis. The uniaxials at the end are pinned to the columns or beam. Material nonlinearity as well as geometrical nonlinearity of the frame with the diagonal tension field uniaxials simulating the SPSW is implemented in the analysis. Figure 5 shows the comparison of the results obtained from the uniaxial model and experimental results [4] in the form of hysteresis diagram of storey shear versus storey drift. The predicted result signifies the accuracy of the simplified finite element model of the steel wall system. The advantage of the diagonal tension field uniaxials model over the shell model is in having less computational time. The time required to analyze the uniaxial model was 20 minutes on the Pentium IV (2 Ghz/256 MB Ram) computer, which indicates that the uniaxial model takes about 90 percent less computational time for the example problem ran in comparison with the shell model.

\section{Parameters Affecting the Behavior of the SPSW}

First, several key parameters affecting the overall behavior of the SPSW system such as steel plate thickness, column stiffness, beam stiffness, aspect ratio, and stiffeners are identified. Then, through detail finite element analyses, the influence of each parameter on the behavior of the system is investigated as follows.

3.1. Steel Plate Thickness. Studying the effect of the steel plate thickness in the overall behavior of the SPSW, the diagonal uniaxials model is implemented for analyzing different SPSWs. By changing the thickness of the plate from $1.5 \mathrm{~mm}$ 


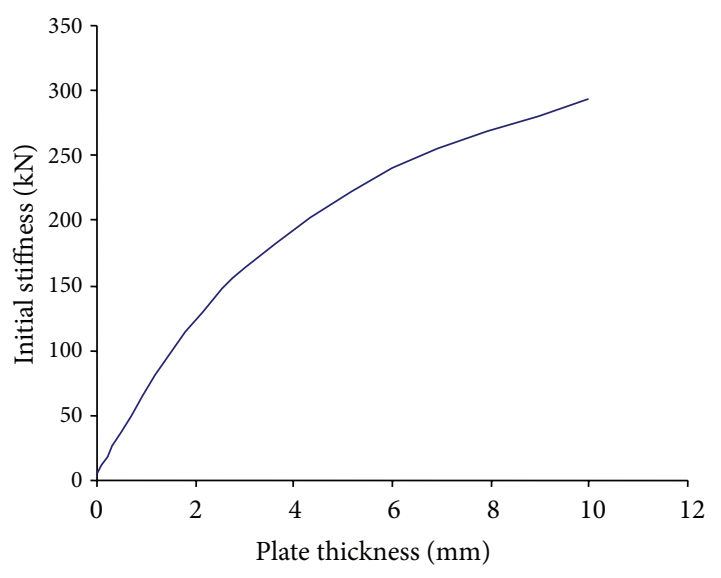

(a)

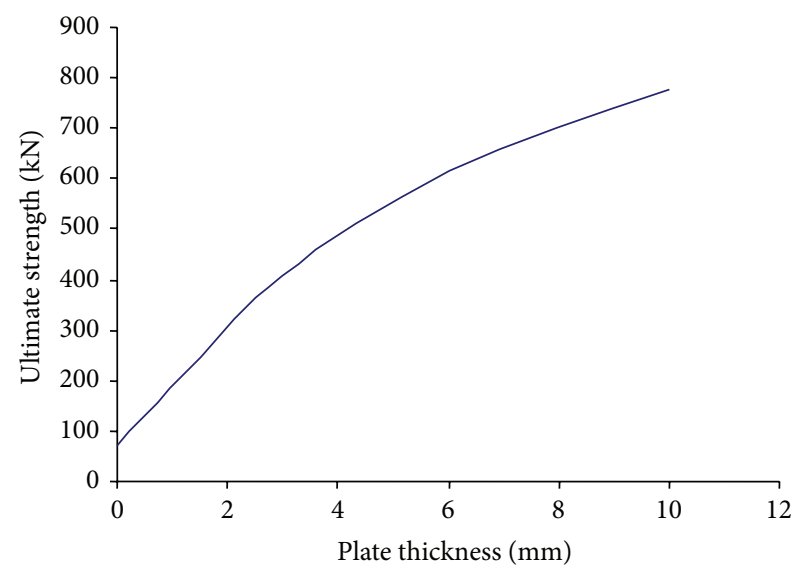

(b)

FIgURE 7: Effect of Plate Increase on Strength and Stiffness.

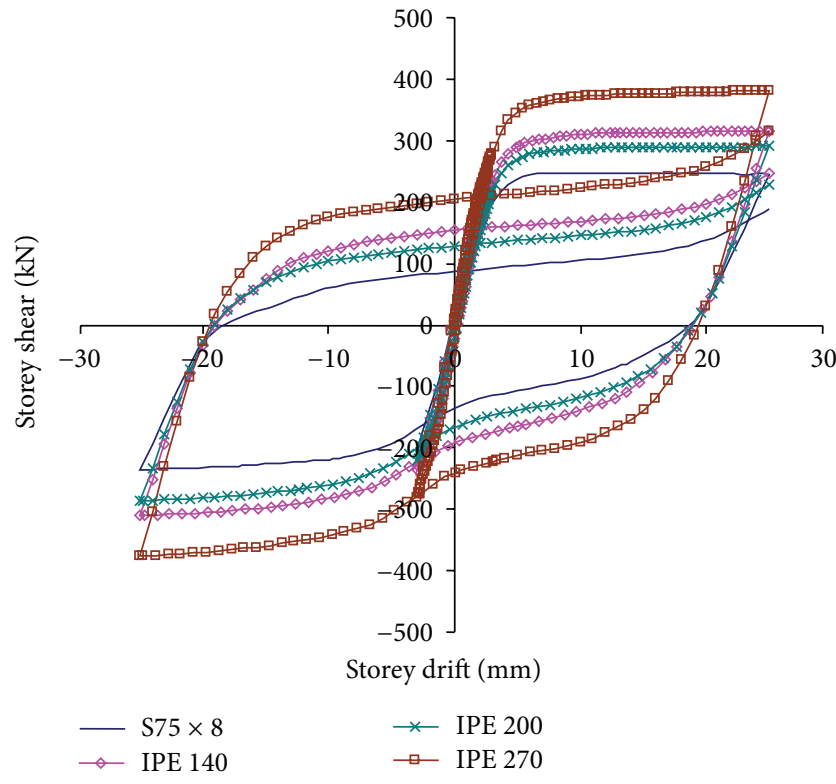

FIGURE 8: Effect of column stiffness on the hysteresis diagram.

to $10 \mathrm{~mm}$, the angle of the uniaxials changes by three degrees which can be neglected. For a certain geometry and wall thickness, lateral load is applied to the SPSW so that the elements with the initial imperfections buckle in order for the uniaxial model to get in tune with the actual behavior of the steel plate. Then the subsequent loading steps and load cycles are applied for further load analysis. Figure 6 illustrates the effect of the steel plate thickness on the overall behavior of the system, which indicates that the energy dissipation of the system increases as the plate thickness increases. By increasing the plate thickness the ultimate strength of the system also increases and the pinching actions of the plate in the unloading and then reloading in the other direction will decrease, showing an improvement in the overall behavior. By increasing the plate thickness, ten times, the energy

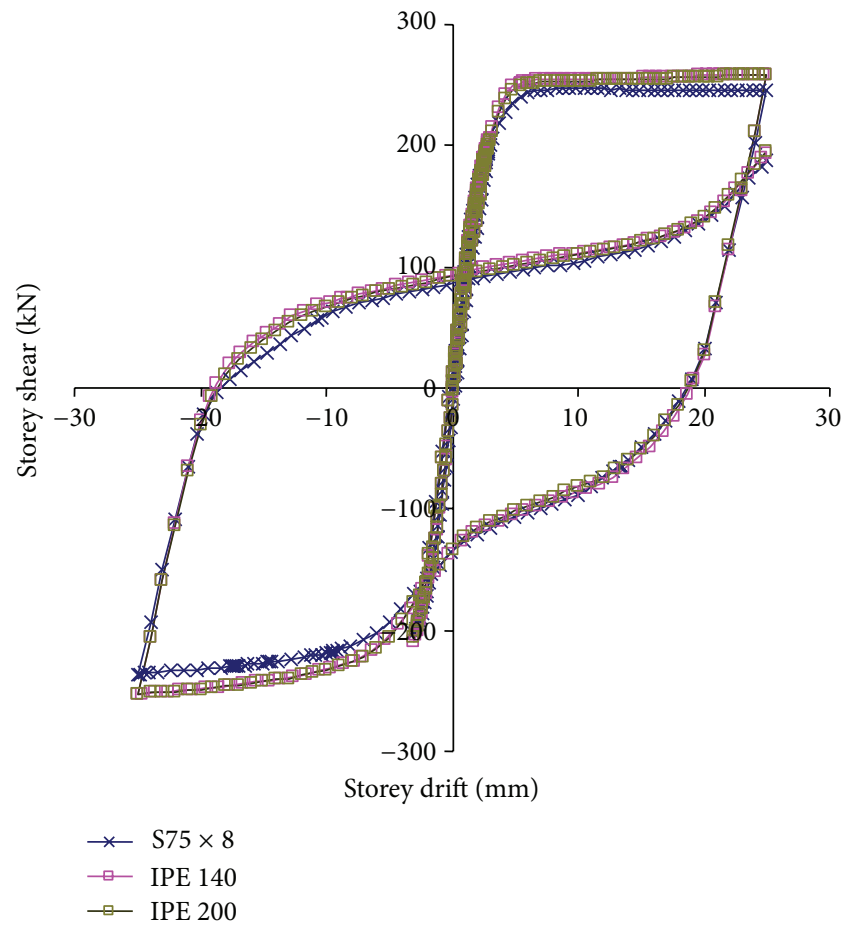

Figure 9: Effect of beam stiffness on the hysteresis diagram.

dissipation of the system also increases, ten times. Figure 7 shows the effect of plate thickness on strength and stiffness of the lateral system. The SPSW systems are usually more flexible than the concrete shear walls. Therefore, when using SPSW in buildings, flexural stiffness must be controlled. Results obtained shown in Figure 7 indicate that the flexural stiffness can be improved very much by increasing the steel plate thickness, and as a result the overturning capacity can be also improved. It is also shown that by increasing the plate thickness ten times, then the flexural stiffness of the system is increased almost six times and the ultimate strength of the system four times. 

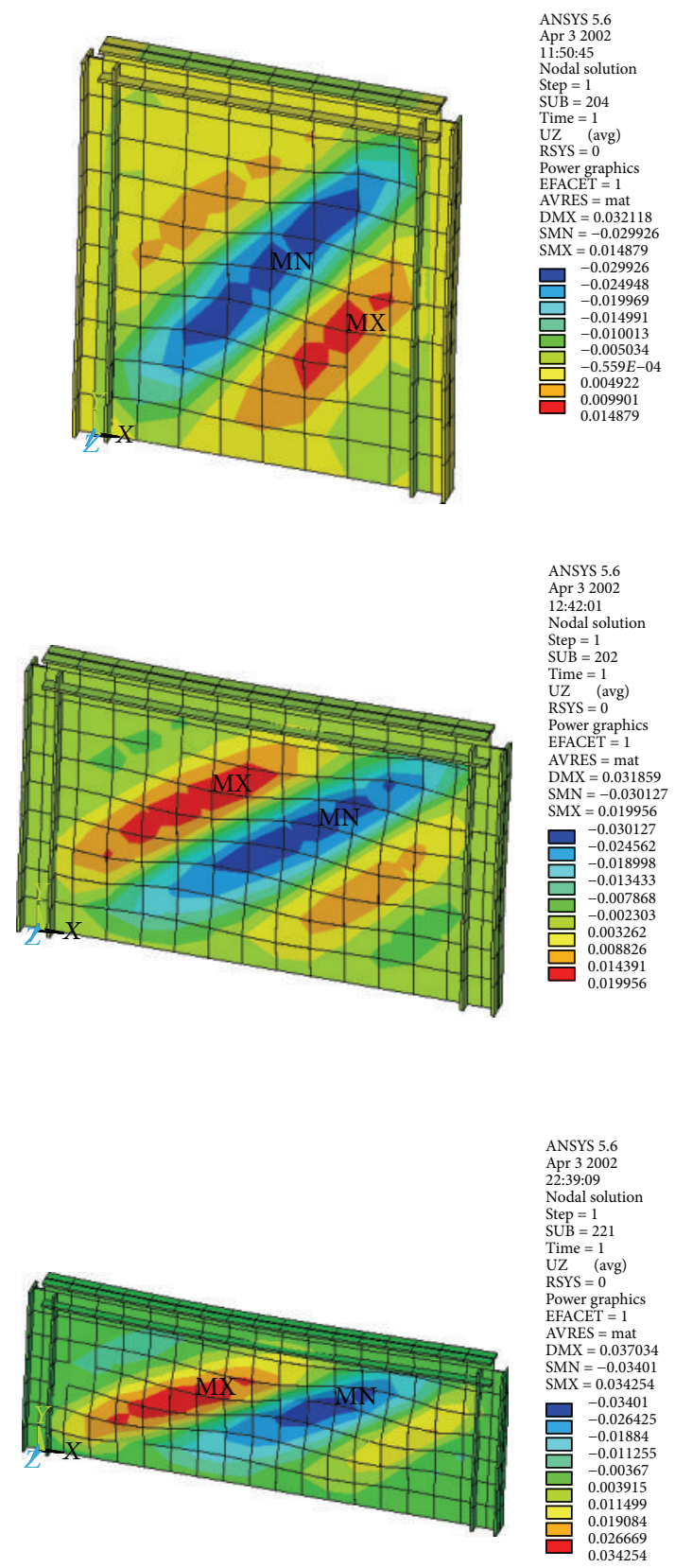
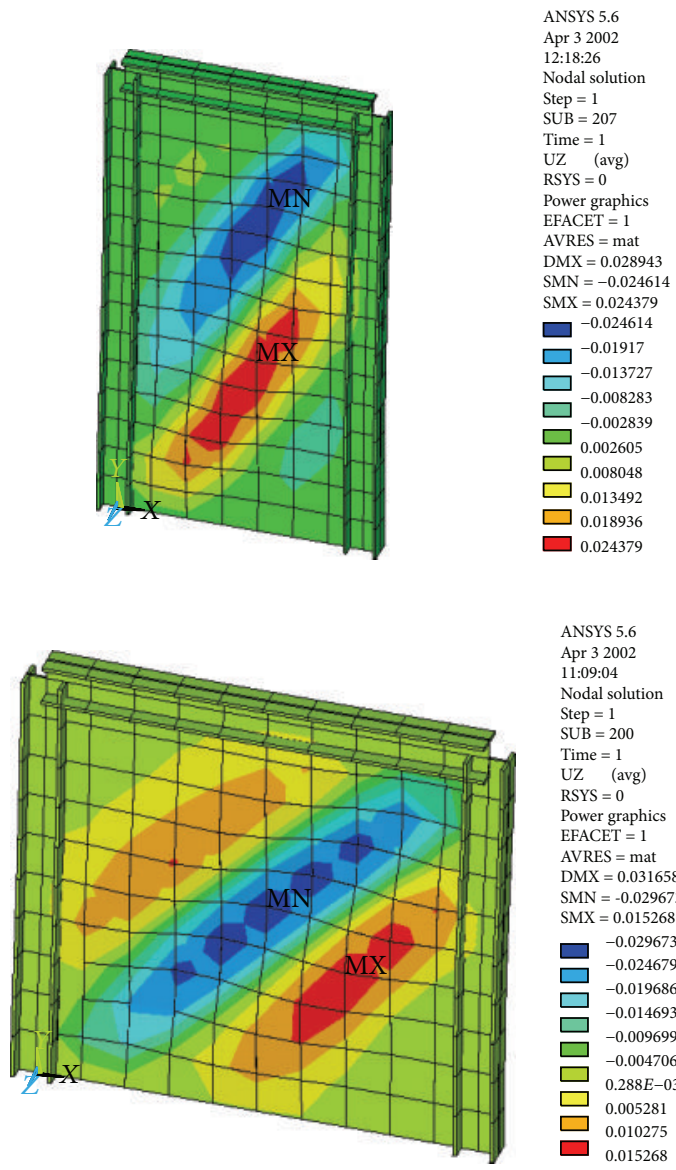

ANSYS 5.6

Apr 32002
$11: 09 \cdot 04$

11:09:04
Nodal solution

Step $=1$

SUB $=200$

Time $=1$

$\mathrm{UZ}$ (avg)
$\mathrm{RSYS}=0$

RSYS $=0$
Power graphics

EFACET $=1$

AVRES $=$ mat
DMX $=0.031658$

SMN $=-0.029673$
SMX $=0.015268$

$-0.029673$

$\square-0.029673$

$\square-0.019686$

$\square-0.014693$

-0.009699
-0.004706

$\square \quad 0.288 E-03$

$\square \quad 0.005281$

$\square \begin{aligned} & 0.010275 \\ & 0.015268\end{aligned}$
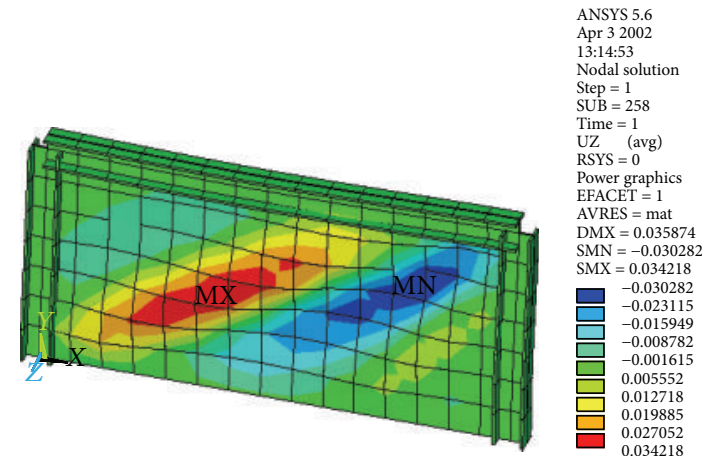

Figure 10: Deformation of steel plate for different aspect ratios.

3.2. Column Stiffness. One of the parameters that may affect the lateral behavior of the SPSW system is the column stiffness. By changing the size of columns in the uniaxial model and applying the cyclic loading, the effect of the column on the overall behavior of the system can be obtained. The result of increasing the column stiffness is shown in Figure 8, which indicates a small increase in energy dissipations. As given in the above figure, the increase in column inertia results in increase in energy dissipation. Although this indicates that the column stiffness increase is not serving the energy dissipation of the system, but still the column must have the required stiffness so that before the tension field is taking place on the diagonal of the plate and plate yielding, the column must not yield nor should the plastic zone take place in the column.

3.3. Beam Stiffness. In the moment resisting frame with steel shear wall, due to existing of plate, the rotation of the connections may not reach the ultimate rotation. In the frames with hinge joints, the connections are capable of taking the twenty to fifty percent of the capacity of the moment connections [6]. Figure 9 shows that increasing the beam stiffness does not have any effect on the overall behavior of the SPSW system. Thus, it can be concluded that the lateral 


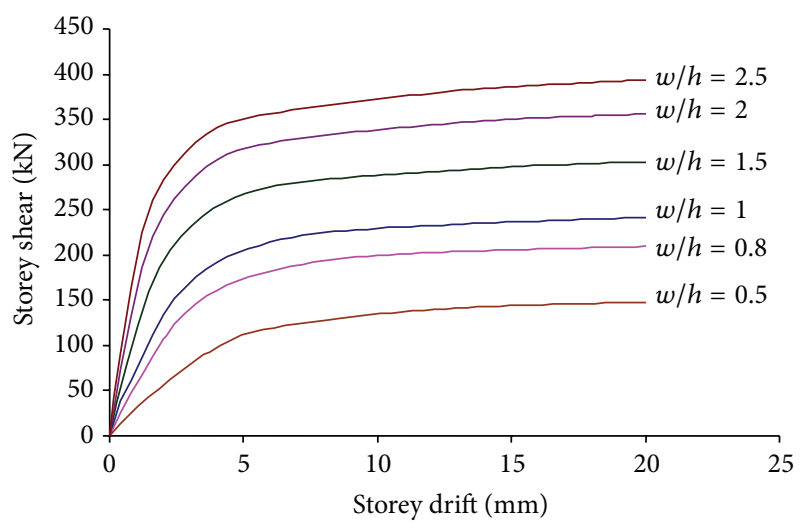

FIGURE 11: Effect of aspect ratio on strength of the system.

load transfer from the SPSW will be through the columns and beams boundary elements, and steel plate wall alone has no effect on the load transfer [6]. From Figure 9 and also from the result of the test specimens subjected to cyclic loadings, it can be concluded that the beam stiffness has little effect on the pinching in the hysteresis diagram.

3.4. Plate Aspect Ratio. The panel length over the panel height ratio, being the aspect ratio of the SPSW of the system, can be an important feature in the design and in the location of the wall. In order to find the effect of the aspect ratio of the wall on the overall behavior of the wall system, the area of plate and the thickness of the steel plate as well as other parameters are held constant and only the aspect ratio is varied. Studying the effect of the aspect ratio is carried out by analysis of the shell computer models. Figure 10 shows the deformed shape of the models for low to high aspect ratios. The computer shell model is chosen since the shear deformation as well as the bending deformation of the plate is required. Figure 11 indicates that as the aspect ratio of the SPSW increases, the energy dissipation and the strength tend to increase. The lateral load resistance in the SPSW is through the tension field action in the plate. As the plate panel increases, the larger diagonal tension field area will be formed in the steel plate and therefore resulting in improving the ductility and better energy dissipation of the system.

3.5. Stiffeners. Stiffeners used in the steel shear walls make the stiffness as well as the energy dissipation increase. Although the stiffeners utilized in the SPSW system can be vertical or horizontal, in practice it is more convenient to use it in vertical direction. The effect of the stiffeners must be compared with increasing the steel plate wall thickness. To find out the effect of stiffeners and in order to have the buckling capabilities within the stiffened plate, a model with very fine elements is required.

In the finite element shell model, the unstiffened steel shear wall plate is divided into 900 divisions $(30 \times 30)$. The undeformed and deformed shapes of the unstiffened plate are shown in Figure 12, in which the buckled behavior of the plate is very much indicated. Then the vertical stiffeners, which are in channel sections, are used in both sides of the wall plate. The undeformed as well as the deformed shape of the stiffened shear plate is given in Figure 13. As expected, utilizing of the vertical stiffeners shows the effect of the stiffeners in preventing the buckling of the plate. Besides improving the initial stiffness in the plate by the stiffeners, the pinching behavior of the plate is also prevented and thus results in increasing the energy dissipation. Although the stiffeners improve the behavior in some sense, but the fabrication of such stiffeners for the SPSW system is time consuming and causes initial defects in the connections (i.e., welds and/or bolts), increases the steel weight, and therefore increases the overall cost. Due to the fabrication difficulties of such system and also to improve the quality of the overall fabrication, it is recommended to use the unstiffened plate with thicker plate instead. In other words, increasing the SPSW thickness is more effective than employing the stiffeners for the SPSW. It must also be noted that increasing the plate thickness is only allowed up to the point where the plate does not become very brittle.

\section{Nonlinear Dynamic Analysis of the SPSW}

In nonlinear time history dynamic analysis, the behavior of the structure can be revealed in details and particularly during the time duration that is subjected to seismic loading. In this category of analysis, the frequency content, peak ground acceleration, and earthquake time domain can be predicted. To investigate the behavior of the SPSW in detail, a nonlinear time history analysis of the uniaxial model is carried out. Elcentro is the earthquake ground motion which is selected for the dynamic time history analysis. The ground motion selected was scaled for the maximum acceleration of $0.35 \mathrm{~g} \mathrm{~m} / \mathrm{s}^{2}$. Figure 14 shows the acceleration response of the wall system for the maximum acceleration of $3.5 \mathrm{~g} \mathrm{~m} / \mathrm{s}^{2}$ subjected to Elcentro ground acceleration.

In dynamic analysis, the effect of earthquake is imposed on the structure for the time period of 30 seconds. Again material nonlinearity as well as nonlinear geometry is included in the analysis. For solving the nonlinear equations directly, which depend on time, Newmark's method with Newton-Raphson procedure is called upon in the computer software. Using the Rayleigh's or proportional damping approach to dynamic analysis, damping of five percent for modes one through five was considered. The hysteresis diagram of the analysis is shown in Figure 15.

The strain energy absorbed by columns is obtained. The energy dissipation in columns is given in Figure 16 for Elcentro ground motion. According to Figure 15, the maximum base shear developed by the structure in Elcentro ground motion is close to $240 \mathrm{kN}$. If the base shear is divided by the weight of the SPSW system which is about $300 \mathrm{kN}$, then the seismic response coefficient of 0.8 is obtained. From this ratio, the accuracy of the dynamic analysis is verified, and theoretically the simplified structural system coefficient $(R)$ can be obtained. Off course for finding the actual structural system coefficient, it is necessary to conduct some experiments. For the sake of the argument, let us 

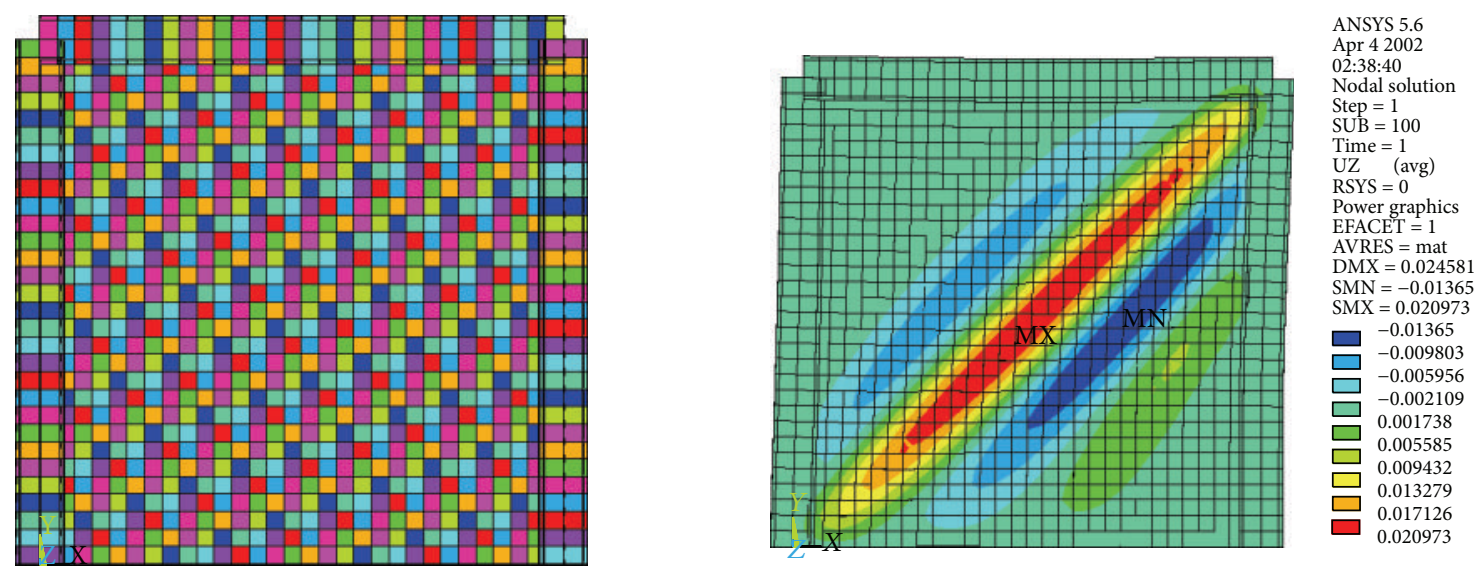

FIGURE 12: Steel plate shear wall without stiffeners.
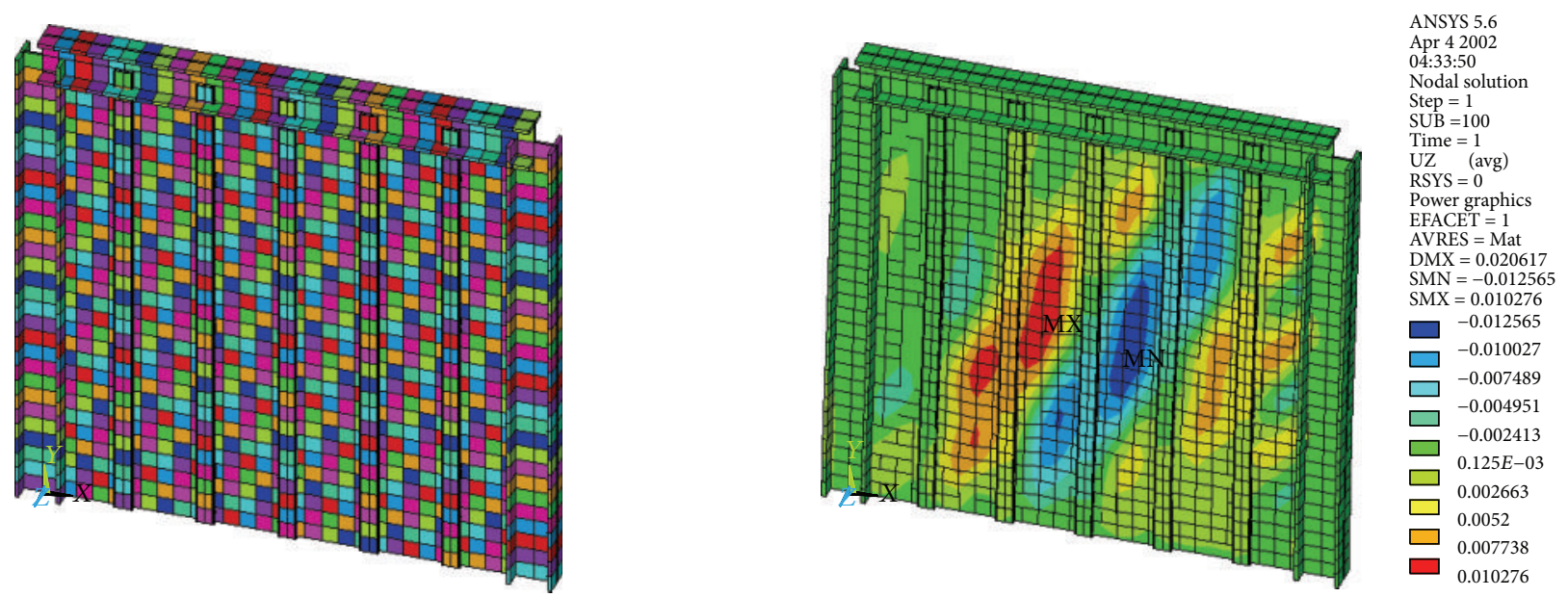

FIGURE 13: Steel plate shear wall with stiffeners.

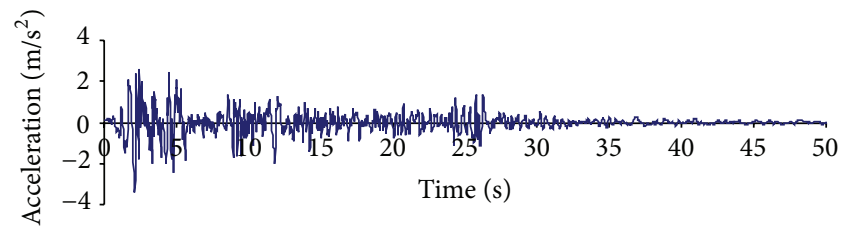

FIGURE 14: Elcentro history record.

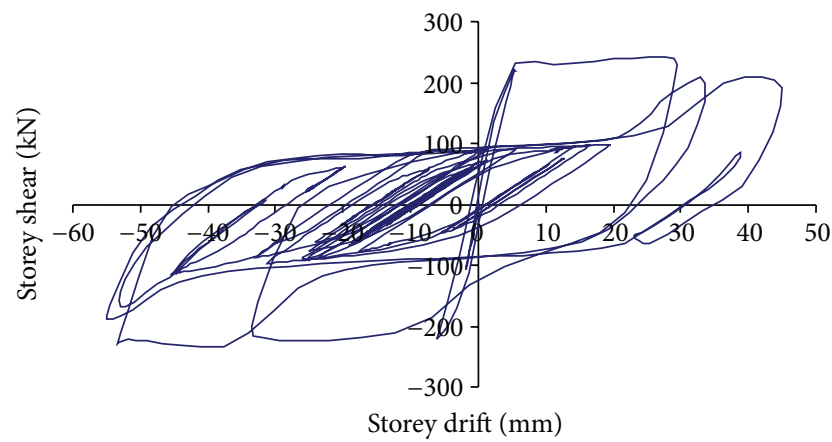

FIgURE 15: Hysteresis diagram of the system (Elcentro).

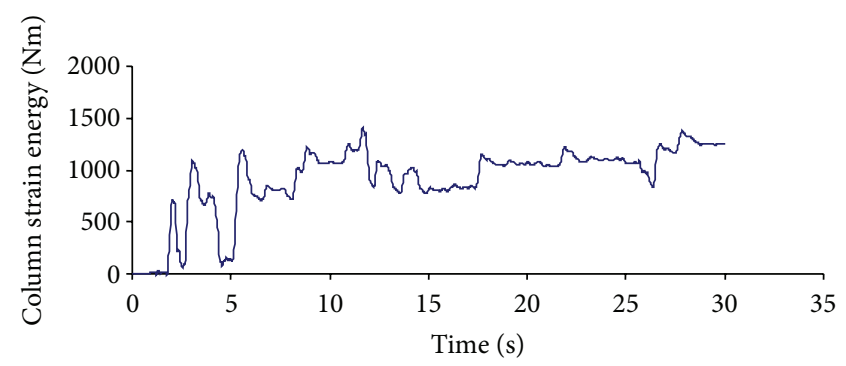

FIGURE 16: Strain energy dissipation through the columns (Elcentro).

calculate the seismic design base shear similar to as proposed by standard building codes,

$$
V=C_{s} W
$$

where the seismic response coefficient, $C_{s}$, is obtained as follows:

$$
C_{s}=\frac{A B I}{R} \text {. }
$$


If we assume $A$, which is the design base spectral acceleration, to be $0.35 \mathrm{~g}$, the importance factor $I$ to be 1.0 , and the response coefficient to be 2.5 , then from (3) the structural system coefficient $R$ is calculated to be 10.93 . This result indicates that the SPSW system has very high ductility and overstrength compared to other lateral structural system.

\section{Conclusions}

In this paper, using the uniaxial diagonal tension model and/or shell elements model of the system, behavior of such system has been acquired. Through the nonlinear dynamic analysis, the behavior of the steel plated shear wall system has shown to have a good ductility specially when it is subjected to cyclic or earthquake excitations. It was revealed that for analyzing such system and in order to lower the time consuming computations and to be more effective, the uniaxial model can replace the shell element model. To understand the behavior of the steel plated shear wall in detail, the significant parameters affecting the overall behavior of the system are recognized. As pointed out, the most effectual parameter on the overall performance and the behavior of the steel plated shear wall system is the plate thickness of the wall. Increasing the plate thickness improves the overall ductility and the overstrength of the system. Increasing the plate thickness has a limitation up to the point where the plate brittleness allows, and for increasing the ductility even further, the system requires stiffeners. It was illustrated that the column stiffness has great effect on the behavior of the system, while the beam stiffness or the aspect ratio of the system showed not as much influence.

\section{Nomenclature}

A: $\quad$ Design base spectral acceleration

$A_{b}: \quad$ Beam cross section area

$A_{c}$ : Column cross section area

$B: \quad$ Response coefficient

$C_{s}: \quad$ Seismic response coefficient

$g: \quad$ Gravity acceleration

$h_{s}: \quad$ Steel plate panel height

I: $\quad$ Seismic importance factor

$I_{c}: \quad$ Column moment of inertia

$L: \quad$ Steel plate panel length

$R: \quad$ Structural system coefficient

$t$ : Steel plate shear wall thickness

$V: \quad$ Design base shear force

$W: \quad$ Weight of the structure

Alpha: Angle of the tension field uniaxial element measured from the vertical.

\section{References}

[1] K. Basler, "Strength of plate girders in shear," ASCE Journal of the Structural Division, vol. 87, no. 7, pp. 150-180, 1961.

[2] P. A. Timler and G. L. Kulak, "Experimental study of steel plate shear walls," Structural Engineering Report No. 114, Department of Civil Engineering University of Alberta, Edmonton, Alberta, Canada, 1983.
3] R. G. Driver, G. L. Kulak, A. E. Elwi, and D. J. L. Kennedy, "FE and simplified models of steel plate shear wall," Journal of Structural Engineering, vol. 124, no. 2, pp. 121-130, 1998.

[4] A. S. Lubell, H. G. L. Prion, C. E. Ventura, and M. Rezai, "Unstiffened steel plate shear wall performance under cyclic loading," Journal of Structural Engineering, vol. 126, no. 4, pp. 453-460, 2000.

[5] M. Elgaaly and Y. Liu, "Analysis of thin-steel-plate shear walls," Journal of Structural Engineering, vol. 123, no. 11, pp. 1487-1496, 1997.

[6] A. Astaneh-Asl, Seismic Behavior and Design of Steel Sheer Walls, Structural Steel Educational Council Technical Information and Product Service, 2001.

[7] NBCC, National Building Code of Canada, Ontario, Canada, 2010.

[8] American Institute of Steel Construction, "Seismic provision for structural steel building," AISC 341-05, ANSI, Washington, DC, USA, 2005.

[9] L. J. Thorburn, G. L. Kulak, and C. J. Montgomery, "Analysis of steel plate shear walls," Structural Engineering Report No. 107, Department of Civil Engineering, University of Alberta, Alberta, Canada, 1983.

[10] P. A. Timler, "Design procedures development, analytical verification and cost valuation of steel plate shear wall structures," Earthquake Engineering Research Facility Technical Report No. 98-01, Department of Civil Engineering, University of British Columbia, Vancouver, British Columbia, Canada, 1998.

[11] ANSYS, Finite Element Method Software, SAS IP, Release 5. 6, 1999.

[12] ATC-24, Guidelines of Cyclic Seismic Testing on Components For Steel Structures, Applied Technology Council, Redwood City, Calif, USA, 1992. 

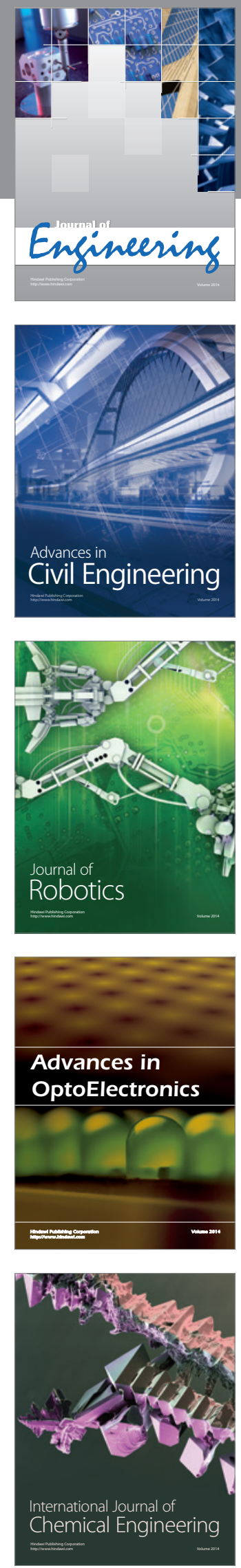

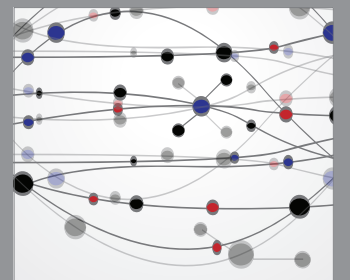

The Scientific World Journal
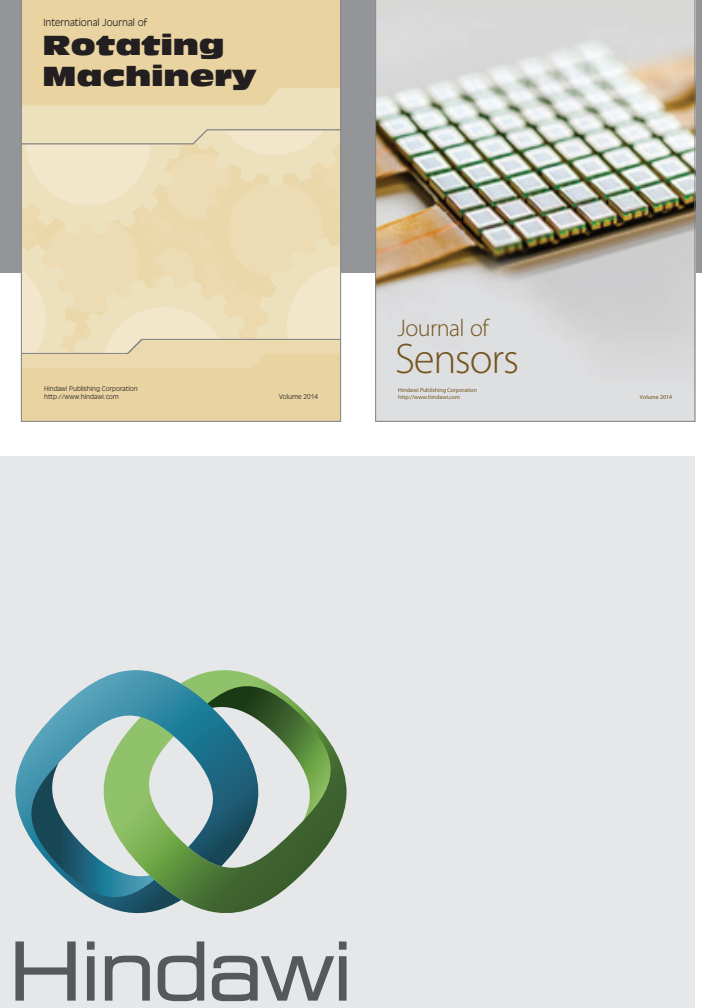

Submit your manuscripts at http://www.hindawi.com
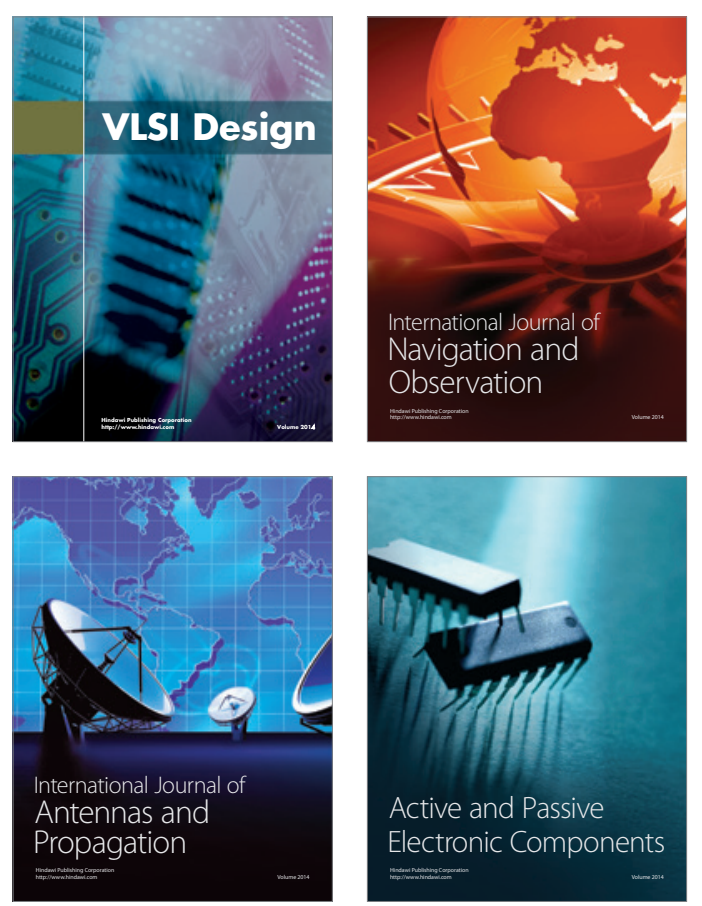
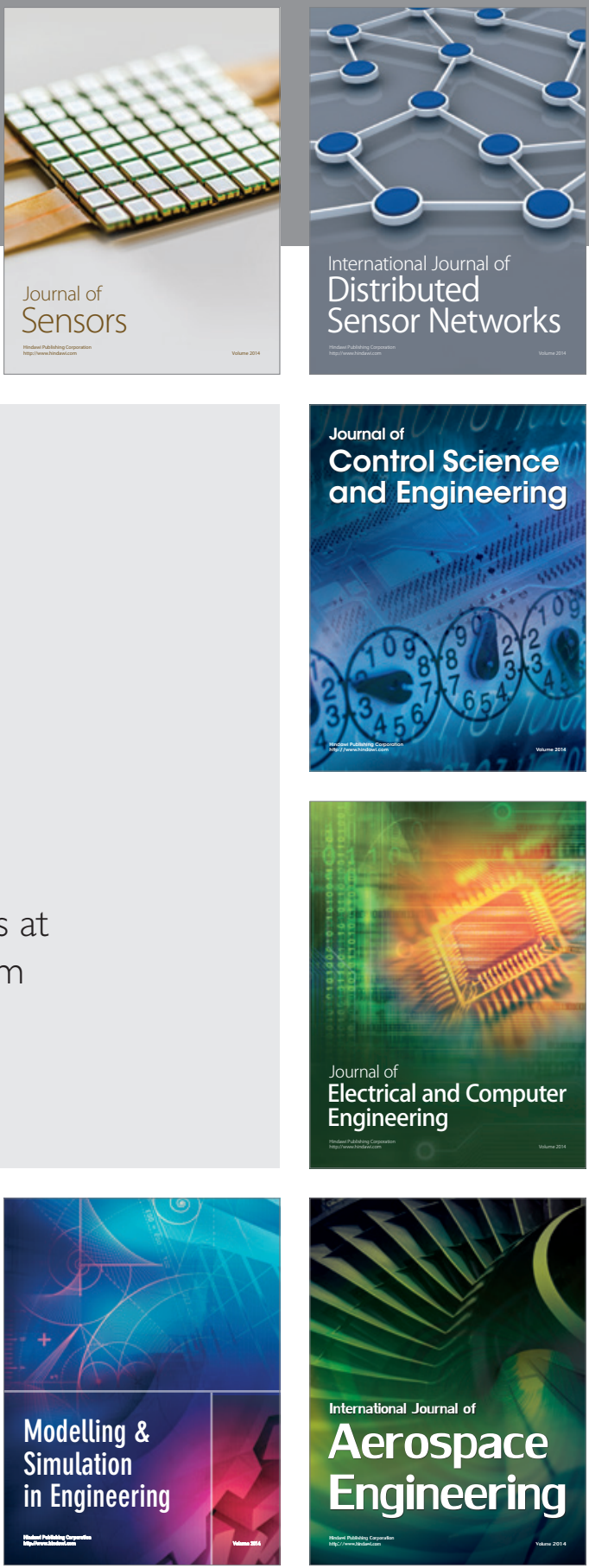

Journal of

Control Science

and Engineering
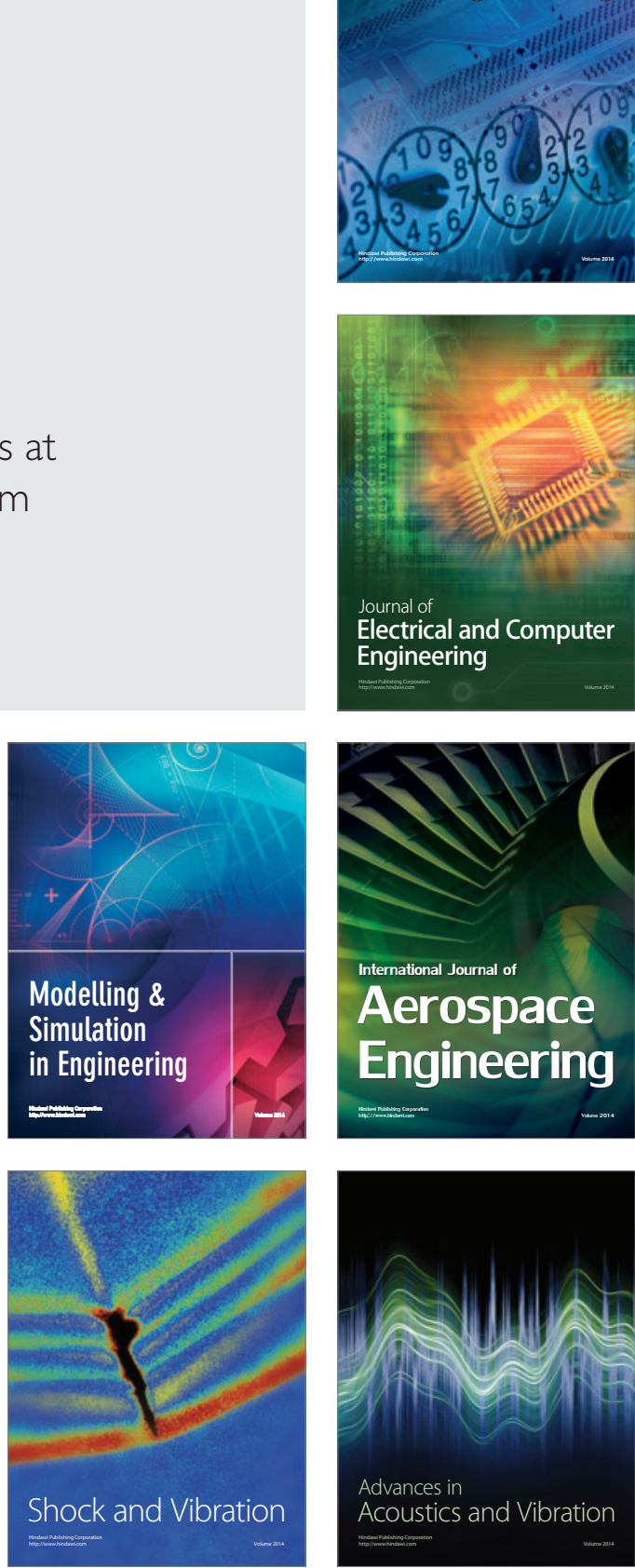